\title{
El ascenso de los judeoconversos al amparo de la alta nobleza en Castilla después de 1492: el caso de Almazán
}

\author{
Máximo Diago Hernando* \\ Instituto de Historia, CCHS, CSIC
}

\begin{abstract}
Contribución al análisis del proceso de integración social de los judíos convertidos al cristianismo en la Corona de Castilla después de 1492, a partir del estudio de un caso local concreto, el de la villa de Almazán, señorío de los condes de Monteagudo. Se centra el análisis en unas pocas familias que destacaron por su elevada posición económica, derivada de su intensa dedicación al comercio y las finanzas, y por la estrecha relación de servicio que mantuvieron con los condes, señores de la villa.
\end{abstract}

PALABRAS ClAVE: Castilla; historia social; siglo XVI; judeoconversos; Inquisición moderna; Lainez.

The Social Promotion of the Converted Jews Under the Protection of the Members of the High Nobility in Castile after 1492: the Case of AlmazÁn.-Contribution to the study of the process of social assimilation of the Jews that adopted the Christian faith in the Crown of Castile after 1492, based on the analysis of a local case, that of the small town of Almazán, subject to the lordship of the counts of Monteagudo. The author pays special attention to a few families of converted Jews that attained a high social and political position, as a result of their notorious role as merchants and financiers, and of the close relationship that they kept, in the role of servants, with the counts, lords of the town.

KeYwords: Castile; Social History; $16^{\text {th }}$ Century; Converted Jews; Modern Inquisition; Lainez.

Sobre la suerte de los judíos convertidos al cristianismo en la Corona de Castilla a partir del siglo XIV, y la actitud que hacia ellos manifestó la sociedad cristiana mayoritaria, en la que se habían de integrar tras la adopción de la nueva fe, se ha debatido mucho entre los historiadores, que han defendido puntos de vista muy dispares al respecto. No cabe duda de

\footnotetext{
*maximo.diago@cchs.csic.es
} 
que al plantearse esta cuestión hay que evitar las generalizaciones, porque las experiencias vividas fueron extraordinariamente diversas, y resulta de todo punto imposible reducirlas todas ellas a un patrón común. Para empezar, hay que diferenciar entre los diferentes momentos cronológicos en que tuvieron lugar las conversiones, y al mismo tiempo también hay que tener en cuenta que no en todas las regiones de Castilla el problema se planteó de idéntica manera. De hecho pueden advertirse contrastes notables incluso entre localidades muy próximas geográficamente entre sí, pero que presentaban estructuras sociopolíticas diferentes, en función de si formaban parte del realengo o estaban sometidas al señorío jurisdiccional de un poderoso miembro de la alta nobleza, y también de la importancia relativa que la comunidad de judeoconversos alcanzaba en el conjunto de la población.

Los problemas a los que tuvieron que hacer frente los judeoconversos antes y después del establecimiento de la Inquisición no resultan sin duda equiparables, y de igual manera tampoco lo son los que afectaron a los miembros de esta minoría en las primeras décadas de funcionamiento de la institución, y en las décadas que siguieron a la publicación del decreto de expulsión de los judíos en 1492.

Todavía continúa generando polémica la interpretación de esta medida de los Reyes Católicos desde la perspectiva de la definición de los objetivos principales que se persiguieron con la misma, y de la identificación de los motivos que llevaron a estos monarcas a adoptarla. Un hecho bien probado es, sin embargo, que fueron muchos los judíos que, ante las nada halagüeñas perspectivas vitales que se les presentaban si persistían en continuar profesando la fe de sus mayores, optaron por aceptar el bautismo para poder residir en territorio castellano. Y fueron las propias autoridades castellanas, desde los reyes para abajo, los que les animaron a que lo hiciesen, presionándoles incluso en algunos casos con insistencia. Hubo conversiones masivas en 1492 y en 1493, y en buena lógica cabe alimentar sospechas sobre la plena sinceridad de las mismas, dadas las circunstancias en que tuvieron lugar, en muchos casos después de haber tomado en un primer momento la decisión de emprender el camino del exilio, pues fueron muchos los que se bautizaron tras haber pasado unas amargas semanas en Portugal.

Si los que se habían convertido en las décadas finales del XIV y a lo largo del siglo XV habían alimentado las sospechas de que eran fal- 
sos cristianos, y en secreto seguían profesando la religión judía, con más razón habría cabido esperar que resultasen sospechosos los que se convirtieron in extremis en los años 1492 y 1493. Por ello ofrece particular interés centrarse en el análisis de las trayectorias de estos judeoconversos de la última «oleada», para poner a prueba algunas de las tesis que sobre el antijudaísmo de inspiración racial de la sociedad castellana han defendido algunos autores.

El que se ha manifestado en términos más radicales en este sentido ha sido Benzion Netanyahu, para quien en la sociedad castellana bajomedieval, y de forma aún más exacerbada en sus sectores populares, estaba arraigada una fuerte animadversión hacia los judíos, que tenía su origen en prejuicios de carácter racial más que religioso, razón por la cual nada podía hacer para desarraigarla la sincera conversión a la fe y prácticas cristianas de los miembros de dicha comunidad. En consecuencia, según este autor, la introducción de la Inquisición por los Reyes Católicos no tuvo como principal objetivo erradicar las prácticas y creencias heréticas de los cristianos de origen judío que no se habían convertido sinceramente a la nueva fe, y seguían profesando en secreto su antigua religión. Para Netanyahu, cuando la Inquisición se introdujo, no existía en los reinos hispanos un auténtico problema de expansión del criptojudaísmo, puesto que la inmensa mayoría de los judeoconversos habían asumido para entonces plena y sinceramente su nueva fe, y la figura del criptojudío estaba en proceso de extinción. Lo que preocupaba verdaderamente al grueso de la población era que la conversión de los judíos al cristianismo les permitiese «infiltrarse» en la sociedad y ocupar posiciones influyentes, que les habían estado vedadas mientras habían profesado la religión hebrea. Por lo tanto, según su punto de vista, los Reyes Católicos accedieron finalmente a implantar la Inquisición, movidos por la presión popular, con el objetivo principal de impedir la integración de los judeoconversos en la sociedad cristiana. Más aún, empleando sus propias palabras: «Se esperaba del tribunal la difamación, degradación, segregación y ruina económica y social de todo el grupo hasta eliminarlo por completo de la vida española» ${ }^{1}$.

Interesa poner a prueba la validez de esta rotunda tesis profundizando en el análisis de las trayectorias de los judíos que se convirtieron a la fe

\footnotetext{
${ }^{1}$ Netanyahu, 2002: 188.
} 
cristiana después de 1492, cuando ya estaba implantada la Inquisición, pues, de ser acertada, resulta lógico pensar que los mismos constituyesen las presas susceptibles de sucumbir con más facilidad ante este afán aniquilador de la «raza judía» que al parecer se había «apoderado» de la sociedad española, y más en particular de la castellana.

El análisis de dichas trayectorias puede llevarse a cabo desde muy diversas perspectivas. Ofrecen indudable interés las monografías centradas en determinados personajes o familias, como la de los Coronel en Segovia o la de los Beltrán en Soria, que, aunque puedan representar casos excepcionales, no dejan de proporcionar información de la que cabe extraer interesantes conclusiones ${ }^{2}$. Adoptando un enfoque algo más amplio, cabe también centrar la atención en el conjunto de familias convertidas al cristianismo en un determinado núcleo de población, que es precisamente la tarea que nos hemos propuesto llevar a cabo en el presente trabajo.

Hemos escogido para ello el caso de la villa de Almazán, de la que eran señores los condes de Monteagudo, del linaje Mendoza ${ }^{3}$, que ofrece notable interés desde esta perspectiva de análisis por varias razones. En primer lugar porque contaba a principios del siglo XVI con una comunidad judeoconversa muy numerosa, que representaba una fracción importante del total de la población de la villa, y que estaba constituida en su inmensa mayoría por familias que se habían convertido al cristianismo después de 1492. Almazán había albergado durante el siglo XV una de las comunidades judías más numerosas y dinámicas de la región ${ }^{4}$. Pero, en notable contraste con lo sucedido en la ciudad de Soria, donde proliferaron los judeoconversos en posiciones influyentes a lo largo de todo este siglo 5 , en Almazán no se tiene noticia apenas de la presencia de judíos convertidos al cristianismo antes de 1492. Por contraste, después de esta fecha pasó a contar con una comunidad de en torno a las cien familias de origen judío que habían adoptado la fe cristiana, las cuales, por una averiguación del tribunal de la Inquisición realizada en esta villa soriana

\footnotetext{
${ }^{2}$ La bibliografía dedicada a los Coronel de Segovia es abundante y se va engrosando cada vez más. Desde la perspectiva que aquí nos interesa resulta particularmente interesante LADERo, 2003. Para el caso de la familia Beltrán de Soria, véase Diago, 1996.

${ }^{3}$ Diago, 1993 b

${ }^{4}$ Cantera, 1976; Castaño, 1994.

${ }^{5}$ Diago, 1992a.
} 
en 1505 , nos consta que vivían concentradas desde el punto de vista topográfico en un barrio bien identificable, que comprendía cinco calles, las cuales estaban significativamente ubicadas dentro del perímetro del que había sido barrio judío hasta $1492^{6}$.

Esta nutrida comunidad de judeoconversos, de origen reciente, y que desde muchos puntos de vista había podido dar continuidad a su régimen de vida tras 1492 sin dramáticas alteraciones, como bien lo testimonia el hecho de que continuasen ocupando el mismo barrio en el que habían vivido como judíos, ofrece un interesante campo de análisis para el investigador que, despojado de prejuicios, trate de indagar sobre las condiciones concretas en que se produjo la incorporación de los judíos a la sociedad castellana de los siglos XV y XVI. Y este es el objetivo que nos hemos propuesto alcanzar mediante el presente trabajo, en el que, teniendo en cuenta la notable incidencia que para la vida sociopolítica de Almazán a fines del siglo XV y en las primeras décadas del siglo XVI tuvo la residencia estable de sus señores, los condes de Monteagudo, tendremos ocasión además de valorar los efectos que para la suerte de los judeoconversos residentes en ciudades de señorío nobiliario pudieron tener sus relaciones con los miembros de la alta nobleza, y determinar cuáles eran las actitudes dominantes entre los representantes de este grupo sociopolítico en lo que respecta a la cuestión judeoconversa.

\section{Los Judíos de Almazán y el PRimer conde de Monteagudo}

Aunque las referencias documentales disponibles para conocer en profundidad las relaciones que los señores de Almazán del linaje Mendoza mantuvieron con los judíos residentes en la capital de su estado señorial son muy escasas, resultan suficientes para confirmar que, al igual que otros muchos nobles castellanos de fines de la Edad Media, estos recurrieron con frecuencia a judíos para que les prestasen servicios, en especial de tipo financiero?. Así, en el momento de la publicación del decreto de

\footnotetext{
${ }^{6}$ Carrete y Fraile, 1987.

${ }^{7}$ Sobre la presencia de judíos en el desempeño de servicios de carácter financiero a miembros de la nobleza castellana proporciona datos CALDERón ORTEGa, 1993. Para la región soriana interesan DiAgO, 1992a y CASTAÑo, 1994.
} 
expulsión en 1492, nos consta que el primer conde de Monteagudo, don Pedro de Mendoza, se servía de judíos para que tuviesen cargo de la recaudación de sus rentas. De ello da fe una provisión de abril de 1493 en la que se recoge la noticia de que ciertos judíos que habían tenido cargo de cobrar rentas pertenecientes a la casa condal, y habían tenido que emprender el camino del exilio, le habían transferido al propio conde ciertas cantidades de dinero que les adeudaban diversas personas por virtud de obligaciones $^{8}$. Nada sabemos en concreto sobre la identidad de estos judíos, pero no hay que descartar que hubiese entre ellos individuos que poco después terminaron recibiendo el bautismo, a los cuales encontramos prestando servicios de carácter financiero al conde de Monteagudo durante las primeras décadas del siglo XVI.

Por alusiones dispersas en documentación de principios del siglo XVI hemos podido constatar que uno de los judíos más hacendados y emprendedores que vivieron en Almazán en la segunda mitad del siglo XV, del que descienden todos los miembros de la familia Lainez a los que nos referiremos con frecuencia a lo largo del presente artículo, Abraham Abén Rodrique, mantuvo estrechas relaciones financieras con los primeros condes de Monteagudo, Pedro de Mendoza y su esposa Isabel de Zúñiga, puesto que en el momento de su muerte estos le debían una elevada cantidad de dinero, próxima a los 5.000 ducados, que se encargó de cobrar su hijo, el que tras su conversión al cristianismo adoptó el nombre de Francisco Lainez, pero que al morir su padre profesaba todavía el judaísmo?.

Francisco Lainez siguió el camino marcado por su padre, Abraham Abén Rodrique, y mantuvo estrechos contactos con la casa condal, aunque la mayor parte de las noticias relativas a los mismos de que disponemos se refieren a la etapa de su vida posterior a su conversión al cristianismo en 1492. Otro tanto cabría decir de sus hermanos, entre los que figura Pedro Lainez, que antes de su conversión se llamaba Rabí Ça Carrillo ${ }^{10}$. En

${ }^{8}$ Archivo General de Simancas [= AGS], Registro General del Sello [= RGS] IV1493, fol. 78. Comisión al bachiller de Portillo.

${ }^{9}$ Esta información y todas las relativas a Abraham Abén Rodrique, identificado como padre de Francisco Lainez, proceden de Archivo de la Real Chancillería de Valladolid [= $\mathrm{AChV}]$, reales ejecutorias [= RE], 350-65 (19-X-1521).

${ }^{10}$ Es el único de los hermanos del que conocemos el nombre judío. A título de 
su caso llama la atención, sin embargo, que antes de 1492 ya había tenido una importante actividad como recaudador de rentas al servicio de miembros de la alta nobleza. En concreto nos consta que había servido en estos menesteres al duque de Medinacelii", pero no consideramos improbable que también llegase a desempeñar la misma función al servicio de su señor, el conde de Monteagudo, y se contase entre los judíos que, según este noble, tenían cargo de la recaudación de sus rentas en el momento de decretarse la expulsión.

La escasa documentación conservada nos proporciona en cualquier caso algunos otros indicios que sugieren que el primer conde de Monteagudo se mostró protector hacia los judíos, llegando incluso a proporcionar amparo a algunos que acudieron a su estado huyendo de castigos o represalias de otros miembros de la nobleza con señoríos en el entorno de Almazán. Desde este punto de vista es muy revelador el caso de Yuçé Paçagón, su esposa y otro judío llamado Vidal Françés, hacia los que había manifestado enemistad el señor de la villa de Serón, Sancho de Rojas, hasta el punto de haber ordenado embargarles sus bienes. Dichos judíos estaban residiendo en una aldea de Almazán, llamada Velilla, hasta la que acudieron armados un grupo de vasallos del señor de Serón, encabezados por el alcaide de la fortaleza de esta villa fronteriza, Mosén Bernal Sánchez, quienes los tomaron presos y se los llevaron consigo a la jurisdicción de Serón, suscitando la comprensible ira del conde de Monteagudo por el grave acto de violación de su señorío jurisdiccional cometido por los vasallos de Sancho de Rojas ${ }^{12}$.

En el momento de la publicación del decreto de expulsión no podemos afirmar con seguridad cuál fue la actitud que los condes adoptaron ante una medida que les afectaba muy seriamente, por la elevada importancia porcentual que los judíos alcanzaban en el total de la población residente

hipótesis cabe plantear que rabí Yuçé Abén Rodrique, y Jacó Abén Rodrique, su hermano, judíos vecinos de Almazán mencionados en un documento de mayo de 1492, fuesen otros dos de los hermanos Lainez, hijos todos de Abraham Abén Rodrique. Vid. AGS, RGS, V-1492, fol. 438.

${ }^{11}$ Sobre la participación de Rabí Ça Carrillo en la recaudación de rentas del duque de Medinaceli en compañía con dos judíos de Sigüenza, véase CASTAÑo, 1994, 222-223.

${ }^{12}$ Comisión al licenciado Sebastián de Balboa, del Consejo Real, para conocer de este asunto, en AGS, RGS, I-1490, fol. 187. 
en Almazán, la capital de su estado señorial. Ciertamente los condes, para quedar en alguna medida compensados por la pérdida de tan gran número de vasallos, recibieron de los reyes, al igual que otros muchos miembros de la alta nobleza castellana, un privilegio por el que se les concedían los bienes que dejaban atrás en su estado señorial los judíos forzados a tomar el camino del exilio ${ }^{13}$. No obstante, cabe presumir que para ellos había de resultar preferible conservar los vasallos antes que unos bienes que sin fuerza humana que los hiciese fructificar necesariamente quedaban muy devaluados. Por ello consideramos muy probable que se movilizasen para lograr la permanencia del máximo número posible de sus vasallos judíos, y el regreso de muchos de los que inicialmente habían optado por marchar a Portugal. En la documentación no hemos encontrado, sin embargo, noticias que corroboren de forma explícita esta hipótesis, ni tampoco relativas a intercesiones a favor de los nuevos conversos, como la que realizó el duque de Alburquerque en 1493 para que dos judíos vecinos de Cuéllar que se habían convertido al cristianismo que tenía presos en Segovia el corregidor Día Sánchez de Quesada, acusados de haber sacado moneda y cosas vedadas al tiempo de su expulsión, fuesen liberados ${ }^{14}$.

Lo cierto es que muchos de los judíos de Almazán que habían inicialmente optado por el destierro regresaron a los pocos meses, sin que se les planteasen dificultades reseñables para reemprender sus vidas y retomar el control de sus haciendas y patrimonios en el estado en que los habían dejado al emprender el camino del exilio. Y que el conde debió tener un fuerte interés en que se quedasen nos lo prueba también, por vía indirecta, la denuncia presentada por uno de los hijos del ya mencionado Abraham

${ }^{13}$ AGS, Cámara-Cédulas, 1, 133, 4, Segovia, 5-IX-1494.

${ }^{14}$ SuÁREZ, 1964: doc. 252. Se ha de tener en cuenta que en el momento de la expulsión algunos judíos de Cuéllar tenían a su cargo la recaudación de rentas pertenecientes al duque de Alburquerque, los cuales, habiendo decidido marchar al exilio en un primer momento, regresaron al poco a Cuéllar convertidos. Es el caso de Francisco Sánchez de la Cueva (SuÁrez, 1964: doc. 241), y también de Fernando Pérez de Cuéllar (ol. Mosé Barroso), quien declaró que, habiendo marchado en un primer momento con los demás judíos, decidió al poco volver convertido a Cuéllar «para servir al duque y estar a su sombra», esta declaración en AChV, RE, 127-12 (9-IX-1498). Francisco Sánchez de la Cueva no fue, por otra parte, el único convertido de Cuéllar que adoptó como apellido el de los duques, señores de la villa, es decir, «De la Cueva». Otro caso notable es el de Fernán Gómez de la Cueva (SuÁrez, 1964: doc. 245). 
Abén Rodrique, Fernando Lainez, vecino de Almazán, en 1493, manifestando que se recelaba que el conde de Monteagudo no le permitiría marcharse a vivir fuera de esta villa, como era su intención ${ }^{15}$.

\section{JudeOCONVERSOS AL SERVICIO DE LOS CONDES DE MonTEAGUdO}

La documentación de los últimos años del siglo XV y de la primera mitad del siglo XVI pone de manifiesto que los dos primeros condes de Monteagudo, don Pedro y don Antonio de Mendoza, tuvieron a su servicio, en posiciones de la máxima confianza, a un gran número de judeoconversos, pertenecientes a unas pocas familias que habían adoptado el cristianismo después de 1492, entre las que destaca la de los Lainez por el gran número de miembros de la misma que sirvieron en la casa condal, sobre todo en el desempeño de funciones con una importante vertiente financiera. Así, al menos dos miembros de esta familia sirvieron como mayordomos, primero García Lainez, y luego su hermano Alonso Lainez. Otros dos, Diego Lainez y Juan Lainez, desempeñaron el cargo de contadores ${ }^{16}$, mientras que un quinto miembro, Antonio Lainez, sirvió bastantes años como tesorero.

Paradójicamente no le conocemos el desempeño de ninguno de estos oficios al miembro de la familia que en un primer momento ocupó, según todos los indicios, una posición más influyente en la casa condal, hasta el punto de recibir el honor de ser nombrado alcaide de la fortaleza de la villa señorial de Moñux. Nos referimos a Francisco Lainez, el mayor de los numerosos hijos del judío don Abraham Abén Rodrique. Los indicios que nos ofrece la documentación sobre la estrecha relación que mantuvo este judeoconverso con los condes de Monteagudo, pese a lo reciente de su conversión al cristianismo, son, sin embargo, sumamente ilustrativos. Sorprendente resulta a este respecto la noticia de que el conde de Tendilla le hizo una merced de $100.000 \mathrm{mrs}$ en premio por haber mediado para que

${ }^{15}$ AGS, RGS, VIII-1493, fol. 133.

${ }^{16}$ Juan Lainez, probablemente el padre del jesuita, era contador en 1532 Vid. AChV, Pleitos Civiles [= PC], Masas, Fenecidos [= F], Caja [= C.] 4-6. Diego Lainez, que figura entre los que acudieron al concurso de acreedores a los bienes del segundo conde tras su muerte en 1547. AChV, PC, Fernando Alonso, F, C. 967-8. 
se llevase a efecto el casamiento de su hija María de Mendoza con el segundo conde de Monteagudo ${ }^{17}$. Por otra parte el propio Francisco Lainez en su testamento otorgado en el año 1520 dejó una buena prueba de la estrecha relación que había mantenido con su señor el conde al reconocer que «me ha hecho mucha falta su ausencia» ${ }^{18}$, para después suplicarle que «sea favorecida mi mujer y mis cosas, como yo siempre tuve deseo a su señoría y a sus cosas».

En la estrecha relación mantenida por este judeoconverso con la casa condal debió desempeñar sin duda un papel fundamental su notoria capacidad para la prestación de servicios financieros. Así, nos consta que, siguiendo el ejemplo de su padre, efectuó importantes adelantos de dinero a los primeros condes de Monteagudo, pues la primera condesa, Isabel de Zúñiga, hizo mención expresa en su testamento del año 1505 a las deudas que tenía contraídas con los hermanos Francisco y Pedro Lainez ${ }^{19}$. Por su parte, tanto el testamento como el inventario post mortem de su hacienda, del año 1520, contienen numerosas noticias relativas a préstamos efectuados a diferentes miembros de la familia condal ${ }^{20}$.

${ }^{17}$ Esta noticia se incluye en las relaciones sobre la composición de la hacienda de Francisco Lainez que se aportaron en el pleito que siguió su viuda Elena Lainez contra los hermanos y sobrinos de su difunto marido, por el reparto de la herencia. De hecho con el conde de Tendilla se negoció un matrimonio doble, el de su hija María, con el conde de Monteagudo, don Antonio, y de su hijo primogénito, Luis, futuro conde de Tendilla, con Catalina, hermana de Antonio.

${ }^{18}$ El conde había abandonado Castilla en el séquito del emperador Carlos, cuando este embarcó en La Coruña en mayo de 1520. Más detalles en DiAgo, 2013.

${ }^{19}$ El testamento de Isabel de Zúñiga, condesa de Monteagudo, en Archivo Histórico Nacional [= AHN] (Nobleza, Toledo) Osuna, leg. 2023-10.

${ }^{20}$ En el testamento indica que le deben dos hermanos del conde las siguientes cantidades: Doña Inés de Mendoza 27.000 mrs; y don Alonso de Mendoza y su mujer Juana de la Cerda 17.898,5 mrs. En el inventario de escrituras realizado tras la muerte de Francisco Lainez en abril de 1520 se menciona una carta del conde de mayo de 1512 asegurando a Francisco Lainez podría cobrar los 483.000 mrs que le había librado en sus rentas de los sexmos de Tierra de Almazán. También aparece una carta cuenta del año 1494, firmada de la condesa difunta, de lo que se cobró en la feria de mayo y lo que se gastó, que prueba que Francisco Lainez, a los pocos meses de su conversión, acudía a las ferias de Medina del Campo para hacer gestiones por cuenta de la primera condesa de Monteagudo. También se menciona una cuenta de Martín de Castejón, secretario del conde, con Francisco Lainez. Testamento, otorgado en Almazán, 3-IV-1520, e inventario post mortem, pueden consultarse en AChV, PC, Fernando Alonso, F, C. 1358-1. 
Además de Francisco Lainez, otros varios miembros de su familia prestaron continuado auxilio financiero a los señores de Almazán, muy en particular al segundo conde de Monteagudo, que estuvo afectado durante toda su vida por graves problemas de liquidez. Ejemplo notable nos lo proporciona en primer lugar su hermano Alonso Lainez, que sirvió como mayordomo al segundo conde, el cual figura en la larga lista de acreedores que acudieron al concurso cuando este noble se declaró en suspensión de pagos en 1524, reclamando el pago de $350.000 \mathrm{mrs}$ que le debía su señor por el valor de diversos paños y tejidos de seda que le había entregado $^{21}$. En su condición de mayordomo parece que con relativa frecuencia este judeoconverso concertó compras de productos de consumo suntuario a mercaderes de Valladolid por elevadas cuantías de dinero, y, aunque se trataba de mercancías destinadas a la propia casa condal, en más de una ocasión fue él quien fue requerido para efectuar el pago. Así lo testimonia, entre otros, el pleito seguido contra el mercader vallisoletano, Diego de Valladolid, quien le reclamó el pago de cerca de $200.000 \mathrm{mrs}$ que le debía por el valor de mercancías que le había entregado, y que Alonso Lainez se resistía a pagarle con el argumento de que las mercancías eran para el conde de Monteagudo, y por lo tanto Diego de Valladolid debía cobrar lo que se le adeudase por ellas entrando al concurso junto con los demás acreedores del conde ${ }^{22}$.

Problemas muy parecidos a los del mayordomo Alonso Lainez tuvo que afrontar su pariente Antonio Lainez, que fue muchos años tesorero del segundo conde. Así, tenemos noticia de varios pleitos que siguió con mercaderes de Valladolid, por no haber cumplido puntualmente con el pago de las deudas contraídas con ellos. En concreto Pedro Fernández de Portillo les reclamó en una primera ocasión conjuntamente a él y a Hernando Álvarez, vecino de Almazán, 80.000 mrs que le adeudaban por el valor de ciertas mercancías, los cuales fueron obligados a abonar por ejecutoria del año $1511^{23}$. Pocos años después, en 1518, la misma Chancillería de Valladolid volvió a obligarle a abonar a este mercader vallisoletano $22.658 \mathrm{mrs}$ que le adeudaba por el valor de ciertas mercancías que por cuenta suya había

${ }^{21}$ Diago, 2013.

${ }^{22}$ AChV, RE, C. 381, X-1525. Ejecutoria a petición de Diego de Valladolid, por la que se condena a Alonso Lainez a pagarle $198.969 \mathrm{mrs}$.

${ }^{23}$ AChV, RE, 261-40, Valladolid, 5-III-1511. 
comprado Gracián de Santa Cruz, judeoconverso vecino de Almazán ${ }^{24}$. Y, por su parte, en 1509 fue el mercader vallisoletano Diego de Valladolid el que consiguió ejecutoria a su favor, por la que se obligó a Antonio Lainez, conjuntamente con otros dos vecinos de Almazán llamados Antón Gómez y García Gonzalo, a pagarle $40.600 \mathrm{mrs}$ que le adeudaban ${ }^{25}$. En todos estos casos el origen de las deudas estaba en la compra de mercancías, pero parece bastante probable que el auténtico destinatario de las mismas fuese el propio conde de Monteagudo, quien, no obstante, evitaba obligar sus propios bienes a la paga, por lo que eran sus criados con mayor capacidad financiera, o los representantes de sus vasallos encargados de la recaudación de impuestos, los que en primer lugar eran llamados a responder cuando se producían demandas de los acreedores ${ }^{26}$.

Teniendo en cuenta todo esto, no podemos dejar de concluir que la estrecha relación que varios de los más destacados miembros de la familia judeoconversa de los Lainez mantuvieron con los señores de Almazán a principios del siglo XVI, debido precisamente al papel central que en la misma desempeñó la prestación de servicios financieros, fue una relación cargada de riesgos. No fueron ellos, sin embargo, los únicos que se vieron afectados por esta paradoja, sino que hubo al menos otro personaje perteneciente al círculo de más estrechos colaboradores del conde, su contador Gómez Ruiz de Mercado, que también sufrió en sus propias carnes las consecuencias de la falta de estabilidad de las finanzas de la casa condal durante toda la primera mitad del siglo XVI, y a pesar de ello permaneció inquebrantablemente al servicio del segundo conde hasta su muerte ${ }^{27}$.

Los Lainez, al igual que Gómez Ruiz de Mercado, con relativa frecuencia se vieron en aprietos financieros por motivos en los que una parte importante de la responsabilidad radicaba en el propio conde. Pero parece que se trató de un riesgo que asumieron gustosos porque a cambio alcanzaron una envidiable posición de preeminencia e influencia en la sociedad ad-

${ }^{24}$ AChV, RE, 325-49, Valladolid, 25-II-1518.

${ }^{25}$ AChV, RE, 235-19, Valladolid, 22-V-1509.

${ }^{26}$ Más detalles sobre las presiones que ejerció el segundo conde de Monteagudo sobre sus criados y vasallos para que saliesen fiadores en sus contrataciones en Diago, 2013.

${ }^{27}$ Más detalles sobre la relación entre el conde don Antonio y su contador Gómez Ruiz de Mercado en Diago, 2013. No hay constancia de que este individuo fuese de origen converso. 
namantina, como tendremos ocasión de comprobar más adelante. Por el momento interesa advertir, no obstante, que además de los miembros de esta prolífica familia otros varios notorios judeoconversos residentes en Almazán a principios del siglo XVI mantuvieron una muy estrecha relación con los señores de la villa. Cabe destacar desde este punto de vista la figura de Álvaro de Luna, quien, por lo demás, estaba emparentado con los Lainez, al haber casado con Catalina Lainez, hermana del licenciado Lainez, médico $^{28}$. De su estrecha relación con el conde de Monteagudo, don Antonio, nos da idea el hecho de que cuando en 1510 este y su único hermano varón, el señor de Tejado don Alonso de Mendoza, precisaron que se les nombrase curador, por ser ambos mayores de 14 años pero menores de 25 , fue precisamente este judeoconverso el designado para desempeñar tal función $^{29}$. Por otra parte, por estos mismos años lo encontramos participando en algunos acontecimientos de la vida política de Almazán que ponen bien en evidencia su condición de hombre de confianza del señor de la villa. En concreto cabe destacar que en febrero de 1513 estuvo a su lado en una acción de fuerza perpetrada contra el monasterio de Santa Clara de Almazán, en el que ambos penetraron rompiendo una pared, al frente de gran número de gente armada, tras lo cual se llevaron por la fuerza a la abadesa y monjas a un mesón de la villa que al parecer servía a la vez de burdel ${ }^{30}$. Por otro lado, su notoria influencia política queda también puesta de manifiesto en la sorprendente frecuencia con que desempeñó en las primeras décadas del siglo XVI los oficios de regidor y alcalde ordinario de Almazán, que eran de duración anual, a los que además accedió por el cupo de la mitad del oficios que correspondían al estamento hidalgo, pese a que, paradójicamente su hermano Ximeno de Luna formó parte del estamento pechero ${ }^{31}$.

${ }^{28}$ CARrete y Fraile, 1987: 67 y 70.

${ }^{29} \mathrm{Su}$ nombramiento como curador del conde y su hermano, tiene lugar en Almazán 1-VIII-1510, ante el alcalde ordinario Gonzalo Ruiz de Ledesma. El acta aparece transcrita en diversos documentos. Por ejemplo en AChV, PC, Pérez Alonso, F, C. 847-5, y AGS, Mercedes y Privilegios, 236. Se ha de destacar que Álvaro de Luna presentó como fiadores a Juan de Puelles, hidalgo cristiano viejo, y Juan Lainez, judeoconverso.

${ }^{30}$ AGS, RGS, V-1513. Para encuadrar este episodio en su contexto, véase DiaGo, 2011.

${ }^{31}$ Información sobre los oficios de gobierno desempeñados en Almazán por los hermanos Álvaro y Ximeno de Luna, en Diago, 1993c: 138-139. Ximeno de Luna, pese a su inferior posición sociopolítica, traducida en su pertenencia al estamento pechero, también 
Que hubo un elevado porcentaje de judeoconversos en el círculo de criados de la máxima confianza del segundo conde de Monteagudo queda por otra parte bien puesto de relieve en una relación que su primera esposa, la condesa María de Mendoza, presentó en la Corte para su defensa en el pleito que se seguía por el asesinato de Juan Garcés, ocurrido durante la ausencia del conde en Flandes, del que se acusaba a la propia condesa. En dicha lista incluyó a todos aquellos criados de su marido que habían testificado contra ella, a todos los cuales los calificó de «personas sospechosas y viles», que estaban predispuestos en contra suya ${ }^{32}$. Y llama la atención el gran número de judeoconversos que había entre ellos, pues, de un total de dieciséis vecinos de Almazán nombrados, cabe identificar como de origen judío a los siguientes: Álvaro de Luna, Ximeno de Luna, Rodrigo de Torres, Álvaro Daza, Diego Lainez, Diego Vélez, García de Alvez, Hernando Alvez, y Elena Lainez.

\section{INDICIOS DEL RÁPIDO ASCENSO SOCIAL}

La comunidad judeoconversa de Almazán destacó en las décadas inmediatamente posteriores a la publicación del decreto de expulsión de 1492 no solo por el gran número de miembros con que contó sino también por la elevada posición socioeconómica que varios de ellos pasaron a ocupar en la villa, prácticamente desde el mismo momento de su conversión al cristianismo. La reconstrucción de la trayectoria de los hijos y demás descendientes del judío don Abraham Abén Rodrique, que en su gran mayoría adoptaron el apellido Lainez, proporciona abundantes pruebas de este fenómeno, y por ello nos vamos a detener a continuación en proporcionar algunos detalles al respecto.

En primer lugar hemos de llamar la atención sobre el hecho de que todos los hijos de este judío recibieron un privilegio de los Reyes Católicos el 2 de mayo de 1494 por el que se les concedieron generosas exenciones de impuestos que les convertían a efectos prácticos en hidalgos, aunque

estuvo en estrecha relación con la casa condal, pues, como atestiguan los libros de actas de la Mesta, sirvió de mayoral de sus ganados a la condesa de Monteagudo, María de Mendoza.

${ }^{32}$ AGS, RGS, X-1523. Provisión a Alonso Pérez y Juan Ruiz, escribanos públicos de Almazán. 
en el documento no se hizo mención expresa al concepto de «hidalguía» ${ }^{33}$. No se trata de un hecho excepcional o insólito pues en estos mismos meses inmediatamente posteriores a la publicación del decreto de expulsión estos mismos monarcas concedieron privilegios aún más generosos a otros varios judíos que accedieron a bautizarse, todos los cuales presentan como rasgo en común el haber estado al servicio de la Real Hacienda en la recaudación de rentas. Es célebre el caso del judío segoviano Abraham Seneor, y de su yerno Mayr Melamed, que recibieron el bautismo en una solemne ceremonia en el monasterio de Guadalupe, a la que asistieron los reyes como padrinos, los cuales les convirtieron acto seguido en hidalgos de solar conocido, dándoles por linaje el de los Coroneles, antiguo linaje castellano extinto, a la vez que les hicieron merced de sendos oficios de regidor en la ciudad de Segovia ${ }^{34}$. Otro ejemplo notable lo tenemos en el judío soriano Vicen [sic] Bienveniste, que después de marchar a Portugal en 1492 regresó convertido al cristianismo, para recibir de los reyes privilegio de hidalguía para él y sus descendientes en 30 de abril de $1493^{35}$. Este judío había mantenido estrechas relaciones de negocios con el mencionado Abraham Seneor y su yerno, que es probable que trabajasen por convencerle para que regresase convertido al cristianismo a Castilla ${ }^{36}$. Por otra parte también sabemos de múltiples contactos que mantuvieron, tanto él como su hijo Antonio Beltrán, con los Lainez de Almazán, y significativamente también con varios judeoconversos residentes en la ciudad de Sigüenza, que igualmente fueron premiados por los Reyes Católicos con privilegio de hidalguía, en atención a su conversión. Nos referimos a Alvar Pérez y Ruy Pérez de Cusanca y Fernán Gómez de León, que conjuntamente recibieron tal privilegio de los Reyes Católicos el 23 de agosto de $1492^{37}$. Las noticias que proporciona la documentación sobre relaciones de negocios y de parentesco que establecieron estos conver-

${ }^{33}$ El privilegio fue concedido por los Reyes Católicos, en Medina del Campo, 2-V1494, e iba dirigido a Pedro, Hernando, Francisco, Diego, Alonso, García y Antonio Lainez, vecinos de Almazán. Se conserva inserto en varias ejecutorias de hidalguía de la Chancillería de Valladolid, y recientemente ha sido publicado en Martín Galán, 2012.

\footnotetext{
${ }^{34}$ LADERO, 2003.

${ }^{35}$ Diago, 1992c.

${ }^{36}$ Diago, 2002; Álvarez García, 1990.

${ }^{37}$ Martín Galán, 2012: 66-69.
} 
sos seguntinos tanto con los Lainez de Almazán, como con los Beltrán de Soria y los Núñez Coronel de Segovia son numerosos y no hay aquí lugar para detallarlas, pero no dejan lugar a dudas sobre el hecho de que formaban una densa red, de modo que la circunstancia de que todos ellos fuesen generosamente premiados por los reyes por su conversión no cabe interpretarla como mera casualidad ${ }^{38}$.

Martín Galán al comentar el privilegio que obtuvieron los hermanos Lainez en mayo de 1494 ha resaltado que no conllevaba en rigor el reconocimiento para ellos y sus descendientes de la condición hidalga, sino una mera exención de impuestos, en contraste con el resto de privilegios que hemos comentado, que sí conllevaban el reconocimiento explícito de la hidalguía. No le falta razón, pero al mismo tiempo también es cierto que, pese a que en la memoria de todos debía estar el reciente pasado judío de toda esta familia, muchos de sus miembros no tropezaron con ningún tipo de dificultad para hacerse reconocer a todos los efectos la condición hidalga, gracias entre otros muchos factores a que fueron los propios condes de Monteagudo los que lo hicieron posible designándoles para cargos y funciones que solo podían desempeñar los hidalgos, como es el caso, por ejemplo, de la tenencia de fortalezas.

Así tenemos que Francisco Lainez, al parecer primogénito de don Abraham Abén Rodrique, convertido al cristianismo junto con su mujer judía, que adoptó el nombre de Elena Lainez, tras 1492, fue designado por el segundo conde de Monteagudo, don Antonio, alcaide de la fortaleza de su villa de Moñux. Este judeoconverso murió en 1520 sin haber tenido hijos de su matrimonio, pero hasta tal punto había asumido la mentalidad hidalga que decidió fundar un mayorazgo constituido en su totalidad por heredades a favor de uno de sus muchos sobrinos, habiendo recibido para ello licencia del rey en $1512^{39}$. Y resulta revelador comprobar que prefirió para ello escoger a uno por cuyas venas corriese sangre hidalga del mayor prestigio, postergando a los que solo tenían por antepasados a judíos. Prueba de ello es que no escogió a ninguno de los hijos de sus numerosos hermanos varones, todos ellos casados con conversas, sino a un hijo de su hermana, Francisca Lainez,

\footnotetext{
${ }^{38}$ Identificación de las principales familias judeoconversas de Sigüenza, y noticias de interés sobre sus vínculos con las de Almazán en CASTAÑo, 1994, y Martín GaLÁN, 2011-2012.

${ }^{39}$ AGS, RGS, VI-1513.
} 
que había contraído matrimonio con Juan Garcés, un caballero de la villa de Ágreda, perteneciente a un linaje de hidalgos de rancio abolengo, el de los Garcés de los Fayos, que además había destacado como uno de los miembros más encumbrados de la clientela del segundo conde de Monteagudo, pues, además de su contino, fue un tiempo su mayordomo, le sirvió como capitán de los hombres de armas que el conde aportó en 1512 para la conquista de Navarra, y desempeñó un notable papel en la vida política de Almazán en 1521, mientras el conde estaba ausente en Flandes en compañía del emperador Carlos $^{40}$. La concertación del matrimonio de Francisca Lainez, quien, según declaraciones de un testigo ya había estado casada con un judío antes de su conversión al cristianismo en $1492^{41}$, con un acreditado hidalgo de la máxima confianza del conde de Monteagudo, como era el agredeño Juan Garcés, proporciona buena prueba de que la cualidad hidalga de los Lainez fue de facto reconocida desde prácticamente el momento de su conversión al cristianismo, independientemente de que en el privilegio que los reyes les concedieron en 1494 no se hiciese mención expresa a la misma. En cualquier caso, dentro de la propia familia se habría asumido el principio de que era preferible la hidalguía vieja a la reciente, y por ello cuando Francisco Lainez tuvo que elegir un sobrino para fundar en su cabeza un mayorazgo escogió a uno de los hijos varones de Juan Garcés. El elegido fue Garci Garcés, quien, al igual que su tío tuvo también a su cargo la tenencia de la fortaleza de Moñux, y, además, sirvió al conde de Monteagudo como mayordomo.

Por lo demás la documentación proporciona algunos otros indicios concluyentes que no dejan lugar a dudas sobre el hecho de que los hijos de Abraham Abén Rodrique, que abrazaron el cristianismo después de

${ }^{40}$ Abundante información sobre Juan Garcés y sus relaciones con el conde de Monteagudo y otros miembros destacados de la sociedad política adnamantina en los procesos que se siguieron ante el Consejo de las Órdenes contra los hermanos de la condesa de Monteagudo, Bernardino y Antonio de Mendoza, ambos comendadores, de Estremera y Socuéllamos respectivamente, por el asesinato del propio Juan Garcés en diciembre de 1521. En AHN, Órdenes Militares [= OOMM], Archivo Histórico de Toledo, 13.361 y 19.889 .

${ }^{41}$ Juramento de calumnia de Antonio de Mendoza, comendador de Socuéllamos, hermano de la condesa de Monteagudo, acusado de la muerte de Juan Garcés, en AHN, OOMM, Archivo Histórico de Toledo, 13.361. Declara que Francisca Lainez «seyendo judía fue desposada con uno que se dice el doctor de Almazán, y después que se tornó cristiana fue casada con Juan Garcés». 
1492 adoptando el apellido Lainez, disfrutaron desde el propio momento de su conversión de una posición preeminente en la sociedad adnamantina. En este sentido resulta muy reveladora la real provisión de diciembre de 1493 que recoge la solicitud del mercader burgalés Andrés Escobar para que la demanda que había presentado contra los hermanos Francisco, Pedro y Garcia Lainez, a los que reclamaba 400.000 mrs fuese tramitada por el Consejo Real, porque en Almazán ellos eran «personas principales y poderosas, y muy favorecidos por el conde y condesa de Monteagudo» ${ }^{42}$. Ciertamente estos calificativos podían tener algo de exagerados, pero no dejan de resultar chocantes si tenemos en cuenta que los individuos a los que se aplican habían estado profesando el judaísmo hasta hacía pocos meses, y por tanto habían estado formando parte de una minoría marginada.

\section{ACTIVIDADES ECONÓMICAS EN QUE DESPUNTARON LOS JUDEOCONVERSOS ADNAMANTINOS}

La comunidad judeoconversa de Almazán después de 1492 fue muy numerosa, y diversificada. Hubo en ella familias de posición socioeconómica muy elevada, y también abundaron las de condición humilde. No cabe duda, no obstante, de que dicha comunidad contribuyó notablemente a la dinamización de la vida económica de la villa por la intensa actividad desplegada por algunos de sus miembros en aquellos sectores de la economía que más potenciaron el desarrollo y progreso económico.

Entre ellos cabe destacar en primer lugar el comercio de la lana. Para la región soriana esta actividad económica fue fundamental durante un largo período que abarca desde comienzos del siglo XV hasta finales del siglo XVIII, gracias a la fuerte demanda de lanas finas que durante estos siglos existió en numerosos países europeos, que carecían de materia prima local de suficiente calidad para sus manufacturas pañeras. Almazán, por ubicarse en una comarca llana con dedicación preferente al cultivo del cereal, no era la mejor dispuesta para convertirse en un gran centro para el trato de lanas finas, a diferencia de Soria o Ágreda, o de las villas serranas de Yanguas o San Pedro Manrique. No obstante lo cierto es que

\footnotetext{
${ }^{42}$ AGS, RGS, XII-1493, fol. 154.
} 
la documentación acredita que en las últimas décadas del siglo XV y durante gran parte del siglo XVI un pequeño grupo de vecinos de Almazán desarrollaron una notable actividad como mercaderes laneros, que, no obstante, solo en casos excepcionales dieron el salto al gran negocio de la exportación, que es el que mayores beneficios generaba. De hecho, el atractivo que llegó a ofrecer el negocio de la cría de ganados trashumantes para la producción de lanas finas, muy demandadas en el mercado internacional, llevó a varios vecinos de la villa de Almazán a invertir en esta actividad, convirtiéndose en grandes señores de ganados. Pero fue sobre todo con lanas de inferior calidad, procedentes del esquileo del ganado estante y trasterminante que poseían los campesinos de la comarca, así como algunos vecinos de la villa, con las que negociaron los mercaderes avecindados en esta. Este tipo de lanas eran muy demandadas por los fabricantes pañeros de la región soriana y de los Cameros, especializados en la fabricación de paños de baja calidad. Pero llama la atención advertir que en la segunda mitad del siglo XV y la primera mitad del siglo XVI también fueron muy demandadas por mercaderes burgaleses, que es muy probable que destinasen a la exportación las de mayor calidad entre las mismas, en unos momentos en que la cabaña ovina trashumante de la Corona de Castilla no debía bastar para satisfacer la demanda de lanas finas que se estaba disparando en otros países europeos en aquellos momentos.

Pues bien, hasta 1492 prácticamente todas las noticias de que disponemos sobre tratantes de lanas residentes en Almazán se refieren a judíos, lo que sugiere que estos debieron ejercer entonces una suerte de monopolio sobre esta actividad. La relevancia que los judíos adnamantinos alcanzaron en el comercio de lanas queda además puesta de manifiesto por el hecho de que no se limitaron a operar en el entorno geográfico más inmediato de la villa, sino que despuntaron también en comarcas más alejadas, como, por ejemplo, la Tierra de Molina, una de las principales regiones productoras de lanas finas de ganado trashumante de la Corona de Castilla en aquellos momentos ${ }^{43}$.

Varios de estos judíos que habían despuntado como mercaderes laneros lo continuaron haciendo, incluso a mayor escala, tras su conversión en 1492. Un primer ejemplo lo tenemos en los varios hijos de don Abraham

\footnotetext{
${ }^{43}$ Diago, 1992.
} 
Abén Rodrique. Este ya había desplegado una intensa actividad en el trato lanero, negociando no solo en la comarca de Almazán, sino también en la de Atienza, donde tenía a su servicio un judío, que tras su conversión al cristianismo en 1492 adoptó el nombre de Francisco del Águila, quien, entre otras dedicaciones, tenía la de hacer sacas de lana para vender. Y nos confirma la envergadura de sus tratos con lanas la constatación del hecho de que en el momento de su muerte dejó en sus lonjas alrededor de 400 sacas, que se encargó de vender su hijo mayor, el que luego se llamaría Francisco Lainez, a mercaderes burgaleses de la familia Paredes, a quienes concedió aplazamiento de pago ${ }^{44}$.

Nada más sabemos sobre los tratos laneros de este último antes de su conversión, aunque sí disponemos de noticias relativas a su hermano Çag Carrillo, que tras 1492 pasó a llamarse Pedro Lainez, el cual, siendo judío, compraba lanas a campesinos del entorno de Almazán, y revendía sacas a otros judíos adnamantinos que estaban al servicio de exportadores genoveses $^{45}$.

Es muy probable que estos dos hermanos, y alguno más, como, por ejemplo, García Lainez, actuasen en compañía en el trato lanero cuando todavía eran judíos, pues así se desprende de una denuncia presentada en 1493 por un conocido exportador, el burgalés Andrés de Escobar, en la que manifestaba que Francisco, Pedro y Garcia Lainez, le estaban adeudando $400.000 \mathrm{mrs}$ por ajuste de cuentas de los tratos que con ellos había tenido, de lanas que les había comprado y mercancías que les había vendido a cambio, los cuales no lograba cobrar pese a que los plazos de pago hacía tiempo que habían cumplido ${ }^{46}$.

Andrés de Escobar tuvo frecuentes tratos con judíos vecinos de Soria que le vendieron lanas ${ }^{47}$, y sus negocios con los hijos de don Abraham Abén Rodrique debieron obedecer al mismo patrón. De hecho estos, tras su conversión al cristianismo, realizaron frecuentes operaciones de venta de sacas de lana a mercaderes de la ciudad de Burgos que las compraban presumiblemente para su exportación, aunque parte importante de dichas

\footnotetext{
${ }^{44}$ Noticia en AChV, RE, 350-65 (19-X-1521).

${ }^{45}$ Noticias en AChV, RE, 85-22 (VII-1495), y AChV, RE, leg. 44, 18-VII-1495.

${ }^{46}$ AGS, RGS, XII 1493, fol. 154.

${ }^{47}$ Diago, 2002.
} 
lanas debían ser de calidad mediocre, pues procedían del esquile de ganado estante. Desde esta perspectiva cabe destacar la actividad desplegada por Francisco Lainez que, como hemos adelantado, fue el que se encargó de vender en la feria de mayo de Medina del Campo a mercaderes burgaleses las 400 sacas de lana que había dejado almacenadas en lonjas su padre cuando murió. Su interés por el trato lanero queda bien puesto de manifiesto en el hecho de que fue propietario de un lavadero de lanas en la villa de Almazán, y, por otra parte, tanto en su testamento como en el inventario post mortem, ambos del año 1520, abundan las noticias sobre compras y ventas de lanas, concertadas incluso con la propia condesa de Monteagudo, que explotaba una cabaña al cargo de la cual estaba como mayoral el judeoconverso Ximeno de Luna ${ }^{48}$. En particular son dignas de notar desde esta perspectiva las noticias sobre ventas de importantes cantidades de sacas de lana efectuadas a mercaderes burgaleses, a los que concedía aplazamientos de pago relativamente generosos, que podían acercarse hasta los tres años, utilizando las ferias de mayo y octubre de Medina del Campo como referencia para fijar los plazos ${ }^{49}$. En esta misma línea se han de interpretar los contactos que consta que mantuvo con el judeoconverso soriano Antonio Beltrán, el principal exportador lanero residente en la ciudad del Duero en la primera mitad del siglo XVI ${ }^{50}$.

Además de Francisco Lainez otros miembros de su familia vendieron sacas de lanas a mercaderes burgaleses. Es el caso, por ejemplo, de su sobrino Juan Lainez, padre del célebre general de la Compañía de Jesús,

${ }^{48}$ Entre otras referencias del inventario cabe destacar las que hay al libro de recibo de lanas de 1500, al libro de 1505, al libro grande de 1519 de cosas fiadas y lanas.También hay referencias a conocimientos firmados por vecinos de aldeas, obligándose a la entrega de lanas, y a un albalá firmado de la condesa, por el que consta que esta le debe a Francisco Lainez cuatro sacas de lana lavada que están en el lavadero.

${ }^{49}$ Como ejemplo ilustrativo de este tipo de contratos en Almazán, podemos citar el firmado en Almazán 9-II-1520, con Pedro de Castromocho, representante de los mercaderes burgaleses Cristóbal de Haro y Gonzalo de Almazán, a los que vendió ciertas sacas de lana por valor de $171.584 \mathrm{mrs}$ que estos se obligaron a pagar en seis plazos, en ferias de mayo y octubre de Medina del Campo, desde la de mayo de 1520 hasta la de octubre de 1522. Copia del contrato en AChV, PC, Fernando Alonso, F, C. 1358-1.

${ }^{50}$ En el inventario post mortem se hace mención a un «envoltorio con cartas mensajeras de Antonio Beltrán», y a «dos cartas de Antonio Beltrán, de un factor y de cierta contratación de ciertas sacas de lana». Sobre el perfil de Antonio Beltrán como exportador lanero, véase Diago, 2009. 
quien en julio de 1523 vendió en Medina del Campo junto con otro vecino de Almazán llamado Diego González, 127 sacas de lana merina lavada y estivada, procedente del esquileo del año 1521, a los mercaderes burgaleses Pedro de Burgos y Pedro de Cuesvasrubias, a razón de 2.500 mrs por saca $^{51}$. Pero, además de ellos, otros notorios judeoconversos de Almazán desempeñaron un destacado papel en el comercio lanero, algunos de los cuales llegaron incluso a participar en el negocio exportador, aunque con inversiones de pequeña envergadura, como es el caso de Mateo de Luna ${ }^{52}$.

En la primera mitad del siglo XVI, entre otros notorios judeoconversos de Almazán que actuaron como intermediarios que vendían sacas de lana a mercaderes burgaleses cabe mencionar a Ramiro López de Calatayud, quien en 1505 reclamó al burgalés Pedro de Arceo 129.000 mrs que le debía por razón de lana que le había vendido ${ }^{53}$. Otra figura destacada sería la de Gracián de Santa Cruz, que se convirtió al cristianismo tras breve estancia fuera del reino en $1492^{54}$, y al que nos consta que el mercader burgalés Diego Ruiz de Miranda había quedado debiendo 102.000 mrs que cobró tras su muerte, en Medina del Campo en 1515, su hijo Diego de Santa Cruz ${ }^{55}$.

Para fechas más avanzadas resulta obligada la mención a Luis Coronel $^{56}$, que fue un ambicioso hombre de negocios, de marcado talante

${ }^{51}$ Archivo Histórico Provincial de Valladolid [= AHPV], 6814-s.f. Medina, 24-VII1523. Se acordó que el comprador pagase la mitad del valor de las lanas de contado, y el resto por mitad en las ferias de octubre de Medina de 1523 y 1524.

${ }^{52}$ Figura en la relación de exportadores publicada por Lapeyre, abonando derechos aduaneros en 1571 (LAPEYRE, 1981).

${ }^{53}$ AGS, RGS, VI-1505. Provisión a las justicias de Burgos. Noticia de la conversión de Ramiro López de Calatayud tras breve estancia fuera del reino, a raíz de la publicación del decreto de expulsión, en AGS, RGS, III-1501. Provisión al corregidor de Ágreda.

${ }^{54}$ Noticia en AGS, RGS, XI-1494, fol. 218.

${ }^{55}$ AHPV, 7839-303, Medina del Campo, 21-XI-1515. Es probable que la deuda tuviese su origen en una venta de sacas de lana, aunque el documento no lo aclara.

${ }^{56} \mathrm{El}$ apellido Coronel fue llevado por varios judeoconversos de Almazán, y de otros lugares de la geografía soriana, como Ágreda, algunos de ellos emparentados con los Lainez. No hay constancia de que tuviesen parentesco con los Coronel de Segovia, sobre los que trata LADERo, 2003. No hemos podido trazar la genealogía de Luis Coronel, aunque nos consta que estaba casado con una judeoconversa, Francisca de Santa Cruz, hija de Diego de Santa Cruz y Luisa Lainez. Diego de Santa Cruz era a su vez hijo de 
especulativo, y también sirvió al conde de Monteagudo como contador ${ }^{57}$. Buena prueba de su espíritu emprendedor y amante del riesgo nos la proporciona, entre otros indicios, el hecho de que tomó a su cargo en compañía con un acaudalado señor de ganados trashumantes de la ciudad de Soria, Pedro González de Río, de acrisolado linaje de hidalgos cristianos viejos, la recaudación de los derechos aduaneros que se cobraban en los puertos secos de la frontera de Castilla con Aragón entre 1552 y $1555^{58}$. Tuvo a su servicio al ya mencionado Mateo de Luna, por lo que cabe la posibilidad de que las lanas registradas en las aduanas a nombre de este fuesen realmente suyas ${ }^{59}$. De hecho nos consta que él también negoció personalmente con lanas, razón por la cual, por ejemplo, en 1551 y 1552 se le reclamó en la ciudad de Soria el pago de una elevada cantidad de dinero por el recaudador de las alcabalas ${ }^{60}$. A su vez tenemos noticia de una importante operación de venta de sacas de lana que efectuó en 1557 a mercaderes burgaleses, pero conviene precisar que en esta ocasión las fibras procedían del esquileo de sus propios ganados ${ }^{61}$. Porque Luis Coronel llegó a convertirse al final de su vida en un destacado señor de ganados, que combinó la explotación de rebaños churros estantes y rebaños trashumantes que pastaban en verano en las sierras sorianas, con la de rebaños trashumantes que tenían sus agostaderos en la montaña de León, que eran los que producían la lana de máxima calidad y precio. De hecho su interés por este último tipo de explotación se despertó en fecha muy tardía, cuando ya le quedaba poco tiempo de vida, al adquirir, por compra

Gracián de Santa Cruz, de quien acabamos de tratar.

${ }^{57}$ Noticia de los pleitos que tenía con el conde después de haber sido su contador en, Archivo Histórico Provincial de Soria [= AHPS], Protocolos Notariales [= PN], 5-14. Soria, 21-VII-1543. Había sustituido en 1541 como contador a Gómez Ruiz de Mercado. Noticia en AChV, PC, Pérez Alonso, F, C. 47-2.

${ }^{58}$ AChV, PC, Pérez Alonso, F, C. 271-3, y AChV, PC, Moreno, Olvidados, C. 843-6.

${ }^{59}$ Mateo de Luna declaró que había estado en Zaragoza sirviendo como factor en diversos negocios a Luis Coronel, AChV, PC, Fernando Alonso, F. C. 215-7.

${ }^{60} \mathrm{AChV}, \mathrm{RE}, 859-76$.

${ }^{61}$ Por contrato firmado en Vitoria, 14-VII-1557, se vendieron a los herederos de Diego de Carrión y compañía, vecinos de Burgos, 95 cuerpos de lana, procedentes del esquileo de las ovejas, carneros y corderos de Luis Coronel del año anterior, por precio cada cuerpo de lana a 6.300 mrs y de añinos a 5.000 mrs. En AChV, PC, Fernando Alonso, F, C. 215-7. 
concertada en Valladolid en julio de 1555, de Hernando Ochoa, receptor general de la paga de las guardas del rey, una cabaña de 7.804 ovejas mayores, 634 cabras, y 4.452 corderos y corderas, por la que se obligó a abonar en varios plazos la elevada cantidad de $4.238 .000 \mathrm{mrs}^{62}$. A diferencia de los ganados que Luis Coronel venía poseyendo con anterioridad, que también eran relativamente numerosos ${ }^{63}$, estos rebaños que compró en 1555 no llegaron a ser traídos nunca a tierras sorianas, puesto que en invierno pastaron en las dehesas pertenenecientes a la encomienda del Portezuelo, que el propio Luis Coronel había tomado a renta, y en verano fueron llevados a agostar a varios puertos tomados a renta en la montaña de León, mientras que se esquilaban en la sierra segoviana u otro lugar de la submeseta norte cuando iban camino de dichos puertos ${ }^{64}$. Se trató de una compra de marcado carácter especulativo, para la que Luis Coronel demostró no tener suficiente respaldo financiero, pues al final de su vida se vio involucrado en arriesgadas operaciones de cambios $^{65}$, que dieron como resultado que tras su muerte sus hijos se viesen apremiados, para atender las demandas de los acreedores ${ }^{66}$, a vender a un mercader de lanas vecino de Palencia, Andrés Gallo, la cabaña de ganados segovianosleoneses que en 1555 había comprado su padre, a pesar de que todavía no se había terminado de pagar el precio convenido al contador Hernando Ochoa, el que la había vendido a Luis Coronel, y que por consiguiente

${ }^{62}$ Copia del contrato firmado en Valladolid, 3-VII-1555, en AChV, RE, 955-19.

${ }^{63}$ En concreto el ganado trashumante soriano, que pastaba en verano en Tierra de Almazán, y en invierno en la dehesa de San Bartolomé, perteneciente a una encomienda de la que era comendador Lope Hurtado de Mendoza, vecino de Burgos, comprendía en 1558 cuatro rebaños, que sumaban 1.949 cabezas de lanar y cabrío. Noticia en AChV, PC, Pérez Alonso, F, C. 637-7.

${ }^{64}$ Información de interés al respecto en las cuentas de la administración de la cabaña lanar que tras la muerte de Luis Coronel rindió su cuñado Gracián de Santa Cruz, curador de sus hijos menores. En AChV, PC, Pérez Alonso, F, C. 637-7.

${ }^{65}$ Noticia de varias operaciones de cambio con Flandes, a las que Luis Coronel recurrió para financiarse en 1557, en los protocolos notariales de Diego de Espinosa, escribano de Medina del Campo. Se copian varios contratos en AChV, PC, Fernando Alonso, F, C. 2875-1.

${ }^{66}$ Uno de los principales acreedores fue un vecino de Valladolid, Luis Falaguer, quien le prestó importantes cantidades en 1556 y 1557, en AChV, PC, Fernando Alonso, C. 271-1. 
exigió que fuese embargada en tanto no se le pagasen los $1.832 .000 \mathrm{mrs}$ que todavía se le adeudaban ${ }^{67}$.

Luis Coronel terminó sus días, pues, como muchos hombres de negocios que arriesgaron en exceso, en situación de práctica bancarrota, aunque finalmente parece que sus hijos, que en un primer momento habían optado por renunciar a la herencia, lograron recuperar bastante, tras resolverse favorablemente para ellos algunos de los muchos pleitos en que se vieron involucrados, en especial los relacionados con la liquidación de las cuentas del arrendamiento de los puertos secos, que su padre había tenido en compañía con Pedro González de Río. No podemos entrar aquí a proporcionar detalles al respecto. Solo hemos querido hacer una somera mención a estas cuestiones para poner de relieve la relevancia que como hombre de negocios, con intereses muy diversificados, alcanzó el judeoconverso adnamantino Luis Coronel, hombre con talante emprendedor y proclive a embarcarse en arriesgadas empresas, durante la primera mitad del siglo XVI.

Por lo demás, la mayoría de los rasgos que definen su figura desde el punto de vista socioeconómico, también los encontramos en mayor o menor grado en otros varios miembros de la comunidad judeoconversa adnamantina de ese período. Así, el interés por invertir en la explotación de ganados trashumantes lo compartió con notorios integrantes de dicha comunidad como los hermanos Diego y Enrique Hurtado, a los que se atribuyó la posesión de más de 4.000 cabezas de ganado lanar, o Ximeno de Luna, quien sirvió como mayoral a la condesa de Monteagudo ${ }^{68}$. Y, sobre todo, interesa precisar que este interés por la ganadería, aunque probablemente todavía no por la trashumante, ya estaba presente en la comunidad judía de Almazán antes de 1492. Buena prueba de ello nos la proporciona la figura del patriarca de la familia Lainez, Abraham Abén Rodrique, que al morir dejó en Almazán un rebaño de ganado ovino que se estimó que rondaría las mil cabezas, y un centenar de cabezas de ganado vacuno, repartidas entre los términos de Ariza, en Aragón, y Serón, en Castilla ${ }^{69}$.

${ }^{67}$ Noticia sobre los pleitos que se siguieron tras la muerte de Luis Coronel, por demandas puestas por sus acreedores en AChV, PC, Fernando Alonso, F, C. 2875-1; AChV, RE, 937-2 (23-II-1559); y AChV, RE, 955-19.

${ }^{68}$ DiAgO, 1993: 253-254.

${ }^{69} \mathrm{AChV}, \mathrm{RE}, 350-65$ (19-X-1521). 
Por su dedicación al comercio de lanas, y a la explotación de ganados trashumantes, los judeoconversos efectuaron una valiosa contribución a dinamizar la vida económica de Almazán durante la primera mitad del siglo XVI, que, por supuesto, a ellos les debió reportar importantes beneficios que facilitarían su ascenso social. Otra actividad en la que despuntaron fue la del comercio de tejidos y otros productos de importación, en la que también pudieron enlazar con importantes precedentes sentados por los judíos antes de 1492.

La figura de Abraham Abén Rodrique nos vuelve a proporcionar una vez más el mejor ejemplo ilustrativo de la importancia que esta actividad llegó a tener para algunos judíos adnamantinos en la segunda mitad del siglo XV. Nos lo confirma la noticia sobre la presencia entre los bienes que dejó a su muerte ${ }^{70}$ de una «botica» de paños y sedas en la plaza de Almazán, que se valoró en 3.000 ducados de oro, y de una segunda «botica» de mercería en la misma plaza, que había estado a cargo de un judío llamado Barú, que era su factor ${ }^{71}$, y de otro criado, convertido al cristianismo después de 1492 con el nombre de Francisco López, que había pasado a vivir a Atienza. Probablemente la labor de redistribuidor de mercancías llevada a cabo por este judío no se limitaba a la venta al detalle en sus dos tiendas de la plaza de Almazán. Es probable que también hubiese incorporado a su clientela al campesinado de la región que circundaba a Almazán, pues nos consta que tenía a su servicio varios factores, todos ellos judíos, distribuidos por las principales cabezas de jurisdicción de la comarca ${ }^{72}$. Ciertamente no sabemos mucho sobre la labor desarrollada

${ }^{70}$ AChV, RE, 350-65 (19-X-1521).

${ }^{71}$ Debe tratarse del don Barú, que, según información proporcionada por CARRETE y Fraile, 1987: 69, adoptó el nombre de Diego de Salazar. Este, tras su regreso de Portugal, permaneció un año al servicio de Francisco Lainez en Almazán, pero luego se volvió a marchar, según algunos a «Judea».

${ }^{72}$ AChV, RE, 350-65 (19-X-1521). En concreto su factor Paçariel [sic] tenía cargo de sus tratos y hacienda en Monteagudo, Serón, Ariza (Aragón) y Peñalcázar, y sus jurisdicciones. Un factor llamado Cosniel [sic], y luego otro llamado Açán, estuvieron al cargo de la hacienda de Almazán, y su Tierra, y de Soria con la suya. Otro factor llamado Abufavera [¿sic?] gestionó los negocios en Ayllón y su Tierra y en El Burgo de Osma, y por fin otro judío que tras su conversión al cristianismo adoptó el nombre de Francisco del Águila, gestionaba su hacienda en el entorno de Atienza, dedicándose en particular a la compra de lanas. Consta que este Francisco del Águila estuvo dedicado después a la compra de lanas por cuenta de Pedro Lainez, hijo de don Abraham. 
por estos factores, salvo que algunos, muy en particular el de Atienza, compraban y lavaban lanas. Es probable, no obstante, que atendiesen las necesidades de consumo de los campesinos, y les proporcionasen crédito, a cambio de asegurarse en condiciones ventajosas parte de su cosecha de cereal o de su producción lanera.

Sobre la faceta de los judíos de Almazán como tratantes laneros ya hemos hablado. Pero, en una comarca cerealera como la adnamantina, no podían dejar de verse tentados por el trato con granos. Y el caso de don Abraham Abén Rodrique, el patriarca de la familia Lainez, nos lo confirma una vez más. En efecto, en la reconstrucción de la composición de su hacienda en el momento de su muerte se hizo mención a nada menos que 14.000 fanegas de cereal que había dejado almacenadas, y que se valoraron en el entorno de los 14.000 florines $^{73}$. Parte de este cereal procedería de las cosechas obtenidas en las heredades de cereal que poseía en propiedad en las aldeas de Taroda, Adradas, Centenera del Campo y Torluenga, pero también es muy probable que lo obtenido de la producción de dichas heredades se viese considerablemente incrementado por el trato especulativo y la recaudación de rentas, bien eclesiásticas o bien del propio conde de Monteagudo. En cualquier caso la figura de don Abraham Abén Rodrique nos confirma que entre los judíos de Almazán hubo auténticos terratenientes, propietarios de numerosas fincas dedicadas al cultivo del cereal ${ }^{74}$. Esto explica que también los primeros judeoconversos adnamantinos destacasen como grandes propietarios de tierras. Y el mejor ejemplo que podemos traer a colación para demostrarlo es el de Francisco Lainez, hijo del anterior, quien a su muerte en 1520 ya había reunido una gran propiedad en tierras, suficiente para con ella poder fundar un mayorazgo a favor de su sobrino, el hijo de Juan Garcés y de su hermana Francisca Lainez ${ }^{75}$.

\footnotetext{
${ }^{73}$ AChV, RE, 350-65 (19-X-1521).

${ }^{74}$ Por su importancia como propietario de tierras don Abraham presenta evidentes parecidos con don Mosé de Cuéllar, el más hacendado judío de Buitrago en las vísperas de la expulsión (CANTERA y CARRETE, 1972: 34).

${ }^{75}$ En Almazán 9-IV-1516 Francisco Lainez funda mayorazgo en cabeza de su sobrino García Garcés con hacienda valorada en 2.000 ducados, integrada por heredades en Almarail, aldea de Soria, y Nolay, Borjabaz y Momblona, aldeas de Almazán. Copia de la escritura de fundación del mayorazgo en AChV, RE, 374 (XII-1524). En su inventario post mortem del año 1520 se incluyen heredades en Soliedra, Castilruiz, Momblona,
} 


\section{MANIFESTACIONES EXTERNAS DE LA RELIGIOSIDAD DE LOS PRIMEROS JUDEOCONVERSOS ADNAMANTINOS}

$\mathrm{Al}$ abordar el análisis de las manifestaciones de la religiosidad de los judíos que abrazaron el cristianismo en Almazán después de 1492 nos encontramos con un cuadro en el que abundan profundas contradicciones. Por un lado la documentación inquisitorial publicada por Carrete y Fraile contiene numerosas denuncias por prácticas judaizantes presentadas en los años 1504 y 1505 contra un gran número de cristianos nuevos de esta villa soriana, entre los que figuran individuos que cabe incluir entre los de posición social más preeminente de la villa. El caso que más llama la atención es el del matrimonio formado por Pedro Lainez y su mujer doña Aldonza, pues, teniendo en cuenta cuanto hemos dicho sobre la familia del primero, su elevada posición socioeconómica y la notoria influencia que se le atribuía en la casa condal, tan precisada de su asistencia financiera, resulta sorprendente la gravedad de las acusaciones que contra el propio Pedro, y sobre todo contra su mujer, lanzaron los testigos que declararon ante el tribunal inquisitorial en Almazán en 1505. Sin entrar a analizar en detalle el contenido de las mismas, baste con hacer constar que a esta última se le atribuyó el haber pronunciado frases tales como «maldito fuese quien avía vedado el Testamento Viejo» y otras que evidenciaban la nostalgia por el pasado judío, tales como «mejor nos yva antes e más teníamos que agora», $\mathrm{o}$ «[...] mientras fueran judíos nunca les faltara el bien y que les faltaba» ${ }^{76}$.

Testimonios de este género sugieren una muy deficiente integración en la comunidad cristiana de miembros prominentes de la que probablemente era la familia judeoconversa más rica e influyente de Almazán a principios del siglo XVI, aunque habría que tener en cuenta que en 1505 apenas habían pasado diez años desde la formalización de su conversión al cristianismo, por lo que el escaso tiempo transcurrido habría resultado insuficiente para la superación de los obstáculos surgidos. Por otro lado, también se ha de tener en cuenta que, pese a la gravedad de algunas de las

Tejado, Nolay, Borjabaz, Almarail, Cavanillas, Centenera, Torremediana, Matamala y Ciadueña. Además poseía casas en Almazán, Velilla y Matamala, un lavadero de lanas en Almazán y un batán en Matamala, y viñas en Almazán y Matamala.

${ }^{76}$ Carrete y Fraile, 1987: 20, 21 y 24. 
denuncias, la Inquisición no tomó ningún tipo de medida, ni contra Pedro Lainez, ni contra su esposa, por lo que cabe presumir que en el medio plazo los problemas de integración se lograron resolver.

Pero, sobre todo, se ha de tener en cuenta que, junto a estos testimonios de graves dificultades en el proceso de integración, nos encontramos con otros que apuntan en un sentido completamente opuesto. En efecto, continuando con el ejemplo de la familia Lainez, advertimos que otro de sus miembros principales, Francisco Lainez, hermano mayor de Pedro, destaca precisamente por el afán demostrado por hacer pública ostentación de su adhesión a su nueva fe cristiana, que abrazó, junto con su esposa, que adoptó el nombre de Elena Lainez, en 1492. Así, invirtió en torno a 150.000 mrs para edificar una capilla en el monasterio de San Francisco, extramuros de Almazán, destinada para su enterramiento, en la que financió también el retablo. Quiso además demostrar su devoción hacia la orden franciscana haciendo donación a su casa de Almazán de 20 ducados y 20 fanegas de trigo, «por que tengan cargo de rogar a Dios por mi ánima». Y también en la misma línea apunta el hecho de que dos frailes franciscanos del convento adnamantino, fray Pedro de Villabrájima, y fray Francisco de Vergara, asistieron como testigos al otorgamiento de su testamento. Por otra parte, se hizo construir además una tribuna en la iglesia parroquial de San Pedro, en la que se gastó 35.000 mrs, con el objeto de poder asistir a las celebraciones litúrgicas desde un puesto preeminente, que le permitiese marcar las distancias respecto al pueblo llano, conforme a la mentalidad hidalga entonces predominante. Por fin, también dotó con generosidad fundaciones de capellanías y aniversarios de misas, para lo cual hizo donación perpetua al cabildo de clérigos de Almazán de una renta anual de 155 fanegas de pan mediado, situada en ciertas heredades de Almazán y su Tierra, y un censo perpetuo de $1.300 \mathrm{mrs}$ anuales, situado sobre un batán edificado en el río Izana, en término de Matamala de Almazán ${ }^{77}$. Y, por otra parte, las ceremonias que encargó que se celebrasen tras su muerte confirman, por si hubiese alguna duda, su plena adhesión a las prácticas piadosas entonces prevalecientes entre las familias cristianas que aspiraban a que se les reconociese cierto status social. En concreto dispuso en su testamento de abril de 1520 que el día de su enterramiento le honrasen los cabildos de los señores

${ }^{77}$ Archivo Diocesano de Osma, 39-D-1 (memorial de censos del cabildo de Almazán, 1557). 
«caballeros», y los señores abad y cabildo de los clérigos, y el cabildo de Nuestra Señora de Guadalupe de Almazán, y ese mismo día se celebrasen diez misas en el monasterio de San Francisco, otras doce al día siguiente, otras doce al tercer día, y otras doce al cabo de año. Además, ordenó que durante un año llevasen a su sepultura en este monasterio un añal de pan, vino y candela, y se le dijese diariamente en el mismo una misa, pagando 20 mrs al capellán que la celebrase.

De todo lo dicho se deduce que mantuvo una especial devoción hacia la orden franciscana, que al parecer pudo tener su contrapartida en otra de semejante tenor mantenida por su esposa, Elena Lainez, con la orden de Santa Clara. Esto al menos es lo que intuimos de la constatación de que cuando esta, en junio de 1523, en una sorprendente decisión, hizo donación de todos sus bienes a una hija de los condes de Monteagudo, otorgó el documento precisamente en el interior del monasterio de Santa Clara de Almazán ${ }^{78}$. Tanto el monasterio de San Francisco como el de Santa Clara de esta villa soriana fueron comunidades en las que al principio del siglo XVI los condes de Monteagudo desplegaron una intensa actividad intervencionista ${ }^{79}$. Y, por tanto, la evidente inclinación que hacia los mismos manifestaron Francisco Lainez y su esposa pudo en gran medida ser consecuencia de los estrechos lazos que a ambos les unieron con la casa condal. Pero aquí nos interesa sobre todo valorar estas manifestaciones de devoción como prueba de una exitosa integración en la comunidad cristiana, que, en el caso de Francisco Lainez, también resulta confirmada por diversas noticias sobre las estrechas relaciones que mantuvo con algunos prominentes miembros del clero secular. En concreto cabe destacar que entre sus testamentarios designó, junto a varios laicos, al clérigo adnamantino Sancho Fernández, además de al prior del monasterio de Nuestra Señora de Allende Duero de Almazán. Y, por otro lado, también en su testamento encargó a dos miembros del cabildo de la catedral de Sigüenza, el deán, Clemente López de Frías, y el arcediano de Molina, Andrés de Atenas, que asumiesen la tarea de cobrar el dinero que le debían dos mercaderes burgaleses por el valor de unas sacas de lana que les había vendido, por lo que cabe presumir que eran personas de su confianza, y con las que había mantenido una estrecha relación.

${ }^{78}$ Copia de la carta de donación, fechada el 8 de junio de 1523, en AChV, RE, 374-7 (20-XII-1524).

79 Diago, 2011. 
El matrimonio de Francisco y Elena Lainez, tras su adopción del cristianismo en 1492, no escatimó, por consiguiente, en medios por dejar bien puesta de manifiesto su adhesión a su nueva fe, asumiendo en su integridad las prácticas piadosas asociadas a la misma, y manteniendo una estrecha relación con numerosos miembros del clero, tanto secular como regular. Quizás por ello ninguno de los dos nos consta que llegase a despertar en ningún momento las sospechas de la Inquisición. Pero tampoco otros parientes próximos suyos contra los que se elevaron denuncias de cierta gravedad llegaron a sufrir ningún tipo de condena. Es el caso de sus hermanos Pedro Lainez, y Aldonza, su esposa, ya mencionados, pero también de algunos miembros de la familia de generaciones más tardías, como Luisa Lainez, hermana del padre del que fue general de la compañía de Jesús, contra la que ciertamente fue incoado un proceso ante el tribunal de Cuenca en el año 1537, pero que no acabó en condena. Por el momento el único individuo con el apellido Lainez avecindado en Almazán que nos consta que fue condenado como hereje judaizante por la Inquisición fue Alonso Lainez, yerno del doctor Antonio Vélez, que fue relajado en 1541 , al igual que su suegro ${ }^{80}$.

Llama la atención, no obstante, que también entre los miembros de la comunidad judeoconversa adnamantina que ocuparon una posición social más preeminente, y se esforzaron por hacer ostentación de su adhesión a la nueva fe, hubo algunos que terminaron sucumbiendo a la condena del tribunal inquisitorial, aunque la misma recayese simplemente sobre su memoria, al haberse iniciado los procesos contra ellos después de haber fallecido. Un ejemplo notable lo tenemos en el ya mencionado doctor Antonio Vélez, quien estuvo al servicio de los condes de Monteagudo como médico. La documentación consultada no nos ha permitido ciertamente reconstruir su perfil con tanto detalle como el de Francisco Lainez, pero sí nos ha llamado la atención constatar que, al igual que este, costeó la construcción de una capilla funeraria de cal y canto, en su caso en una de las iglesias parroquiales de Almazán, la de San Vicente.

Lo sabemos porque una hermana del segundo conde de Monteagudo, Isabel de Zúñiga, dispuso en su testamento que se edificase en dicha

${ }^{80}$ Referencias varias a estos procesos en Martín Galán, 2012: 56, Carrete y Fraile, 1987, y PÉREZ RAmírez, 1982. Queda pendiente realizar un análisis pormenorizado de los mismos. 
iglesia otra capilla de cal y canto junto a la que había hecho construir dicho doctor ${ }^{81}$. Ciertamente no era la intención de la hija del conde que se la enterrase en dicha capilla, pues prefirió la de sus padres en el monasterio de San Francisco en espera de que se terminase de construir la que había ordenado edificar en el monasterio franciscano de Cornago, villa del señorío de su difunto marido, para que finalmente se trasladasen a ella sus huesos. Mandaba construir la capilla en San Vicente para que se depositasen en ella los restos mortales de su ama, de su amo, y de una hija de ambos. Pero, a pesar de todo, no deja de resultar sorprendente que al redactar su testamento hiciese mención expresa al doctor Vélez y a su capilla, cuando hacía pocos años que se había concluido un proceso que contra este había seguido la Inquisición después de haberse producido su muerte, en el que había sido encontrado culpable, y condenado a la relajación en efigie. No debió considerar doña Isabel de Zúñiga irremediablemente manchada la memoria del que había sido el médico de su familia cuando dispuso de forma explícita que se edificase la capilla que era su intención construir para sus amos, al lado precisamente de la que él había construido. Pero no es este el lugar para entrar a elucubrar sobre las huellas que las relajaciones en efigie dejaban en la memoria colectiva en la Castilla del siglo XVI. Lo que nos interesa resaltar es el hecho, aparentemente contradictorio, de que quien había destinado una parte de su fortuna, trabajosamente reunida mediante el desempeño de la medicina y otras actividades, a financiar la construcción de una capilla funeraria en una iglesia, fuese hallado culpable tras su muerte de haber profesado en secreto el judaísmo. Por supuesto estas contradicciones, y otras de mucha más envergadura, han abundado en los comportamientos humanos y lo siguen haciendo en el presente. Aquí simplemente nos interesa valorarlas como un síntoma de que la incorporación de los judíos a la comunidad cristiana después de 1492 constituyó un proceso complejo, con sus luces y sus sombras, en el que nos podemos encontrar fenómenos que sugieren que la misma se produjo con rapidez y facilidad, junto con otros que invitan a sospechar lo contrario, a veces incluso cuando repasamos la trayectoria de un mismo individuo o de una misma familia.

${ }^{81}$ Testamento de Isabel de Zúñiga, hija del primer conde de Monteagudo, Pedro de Mendoza, y viuda del señor de Cornago y Jubera, Álvaro de Luna, en AHN (Nobleza, Toledo), Osuna, 2188-3-6. 
En un balance global, sin embargo, hay motivos para concluir que finalmente prevalecieron las tendencias a favor de la integración. Así, desde el punto de vista de la asimilación de las creencias cristianas, y sin abandonar el caso concreto de la comunidad judeoconversa de Almazán, no podemos pasar por alto el hecho de que la familia más rica e influyente de dicha comunidad, la de los Lainez, en su tercera generación tras la conversión al cristianismo proporcionó a la Iglesia católica uno de sus teólogos más activos y reputados, el segundo general de la Compañía de Jesús, Diego Lainez ${ }^{82}$. Y, no solo eso, sino que pronto, siguiendo el ejemplo de este, varios hermanos suyos y otros parientes ingresaron en dicha Compañía.

Ciertamente son más escasas, en el estado actual de la investigación, las noticias sobre el ingreso en conventos de monjas de doncellas de la familia. Pero familias judeoconversas de otras ciudades castellanas proporcionan numerosos ejemplos de tales ingresos, a veces en fechas no muy alejadas del momento de la conversión al cristianismo. Y no hay que excluir, por tanto, que un rastreo más intensivo de la documentación pueda proporcionarlos también en el futuro en el caso de Almazán.

\section{CONSIDERACIONES FINALES}

De haber estado tan enraizado el odio contra la «raza judía» del que habla Netanyahu, resulta difícil comprender cómo a la familia Lainez y otras familias judeoconversas de Almazán les resultó posible, después de su conversión al cristianismo en 1492, incorporarse a

${ }^{82}$ Es abundante la bibliografía existente sobre este personaje, y en las obras más recientes es habitual encontrar algunas breves consideraciones sobre su condición de descendiente de judíos, mientras que en las más antiguas o bien se negaba, o se admitía con reservas, cuando no se evitaba decir algo al respecto. Interesa consultar, MARTínEZ de Azagra, 1933; Ribadeneira, 1944, y Cereceda, 1945-1946: Para la reconstrucción de la genealogía de Diego Lainez, y confirmación de la tesis de que todos sus antepasados fueron judíos, tras la publicación de la colección documental de CARRETE y FraILE, 1987, han resultado concluyentes los trabajos de MARTín GALÁN, 2011-2012 y 2012. Prueba del arraigo que en la historiografía ha tenido el prejuicio que consideraba el origen judío como una «mancha» la encontramos en la biografía del padre Lainez, de Cereceda, quien al referirse a su «posible origen judío», habla literalmente de «un defecto en el que no tuvieron culpa alguna», que habían compensado con «grandes y virtuosos hechos», Cereceda, 1945-1946: vol. I, 22 
posiciones de primera fila en la sociedad adnamantina en tan estrecho margen de tiempo. Podría argumentarse que un factor decisivo que jugó a su favor fue la protección que les dispensaron los señores de la villa, los condes de Monteagudo, que no obedecería a motivaciones meramente altruistas, sino que tendría bastante de contraprestación por los valiosos servicios de carácter financiero y de otro tipo que les prestaban, y de los que no podían prescindir.

No hay que excluir, por tanto, que en determinados sectores de la sociedad adnamantina estuviese arraigada una cierta animadversión contra estas familias de nuevos cristianos que, habiéndose incorporado a la comunidad prácticamente a la fuerza después de 1492, inmediatamente se habían encaramado a las posiciones de la máxima influencia. Pero hoy por hoy queda lejos de estar probado que estos sectores se sirviesen de la Inquisición para frustrar los procesos de integración y ascenso de dichas familias, y lograr, en mayor o menor grado, su aniquilación.

Ciertamente, si tenemos en cuenta el gran número de procesos que a lo largo del siglo XVI el tribunal de la Inquisición de Cuenca siguió contra vecinos de Almazán ${ }^{83}$, hemos de admitir que el proceso de integración del centenar de familias judeoconversas que pasó a albergar esta villa soriana después de 1492 no fue un camino de rosas, como el seguimiento de la trayectoria de algunos miembros de la familia Lainez, en particular el de Francisco Lainez, podría invitar a presumir. Hubo resistencias y graves dificultades, que no todos lograron superar con la misma fortuna. Y entre las víctimas de las actuaciones de la Inquisición pertenecientes a la comunidad judeoconversa adnamantina nos encontramos también con individuos de notable relieve político y socioeconómico.

Ciertamente no hemos constatado la existencia de ningún caso equiparable al que se dio en la villa señorial de Buitrago, dependiente de otra rama del prolífico linaje Mendoza, la de los duques del Infantado, donde nada menos que un regidor, el converso Íñigo López de León, acusado de viajar al reino de Portugal a visitar a su padre judío allí residente y de mantener en su casa una «sinagoga»

\footnotetext{
${ }^{83}$ Relación detallada en Pérez Ramírez, 1982.
} 
secreta, terminó siendo condenado en 1519 a relajación, excomunión mayor y confiscación de su patrimonio ${ }^{84}$. Pero un individuo que en vida había alcanzado una posición de influencia política en Almazán equiparable a la de Íñigo López de León en Buitrago, Álvaro de Luna, también llegó a contarse entre los merecedores del máximo castigo impuesto por la Inquisición, con la importante diferencia de que en su caso el proceso se puso en marcha en una fecha muy tardía, cuando ya había fallecido, por lo que la severa condena dictada contra él solo afectó a su memoria, y en cierta medida de forma más material a sus descendientes.

A este respecto llama la atención que en Almazán los tres judeoconversos de mayor relieve sociopolítico castigados con las penas más severas por la Inquisición fueron procesados en la década de 1540 , cuando ya habían fallecido. Se trata, además del mencionado Álvaro de Luna, de su hermano Ximeno de Luna, y del doctor Antonio Vélez, médico del conde de Monteagudo. Los tres fueron encontrados culpables de las acusaciones de judaísmo contra ellos presentadas, y condenados a relajación en efigie. Pero llama poderosamente la atención el hecho de que, cuando la Inquisición hizo sus averiguaciones en Almazán en 1505, ya hubo muchos testigos que atribuyeron prácticas judaizantes a estos tres individuos, sin que ninguna acción se emprendiese entonces contra ellos, por lo que pudieron continuar participando en la vida política de la villa desde las posiciones de máxima influencia, de forma muy evidente en el caso de Álvaro de Luna. Cabe preguntarse entonces por qué se esperó hasta después de su muerte para iniciar procesos contra ellos. La estrecha vinculación que mantuvieron los tres con la casa condal invita a presumir que pudo ser un factor disuasorio para sus enemigos. En el estado actual de la investigación no podemos entrar a hacer más precisiones. Pero lo tardío de los procesos, añadido al hecho de que se llevaron a cabo contra personas fallecidas, arroja una sombra sobre los mismos que no puede ser ignorada a la hora de valorarlos.

Sin duda hubo gradaciones en el éxito alcanzado a la hora de lograr la integración y el ascenso social entre las distintas familias ju-

${ }^{84}$ CANTERA y CARRETE, 1972: 50. 
deoconversas de la Castilla del siglo XVI, y no siempre resulta fácil identificar los factores que las explican. En Almazán la familia Lainez proporciona el ejemplo de éxito más completo en dicho proceso, aunque tampoco estuvo completamente a salvo de amenazas, pues individuos con los que estaba relacionada por vínculos de parentesco más o menos próximo se contaron entre los procesados y, también entre los condenados, por la Inquisición. Pero la mayoría de sus miembros lograron salir indemnes, incluso aquellos contra los que se presentaron más graves acusaciones, como es el caso de Pedro Lainez y de su mujer Aldonza. La presencia masiva de miembros de la familia entre los servidores de los condes de Monteagudo, con destacado papel en la gestión de sus finanzas, es probable que les sirviese como escudo protector, y facilitase su integración y ascenso.

Los Lainez, descendientes del judío Abraham Abén Rodrique, alcanzaron una posición de preeminencia en la primera mitad del siglo XVI que justifica el calificarlos como la familia más rica e influyente de Almazán por debajo de los Mendoza, sus señores jurisdiccionales. Resultaría de interés dar continuidad a las investigaciones para determinar cómo evolucionó dicha posición durante la segunda mitad de dicho siglo y en el siguiente. Podemos adelantar, atendiendo a los indicios hasta ahora reunidos, que aparentemente no lograron mantenerla, pues son otras las familias que en el siglo XVII, cuando los condes de Monteagudo habían dejado de residir habitualmente en su palacio de Almazán, encontramos en la cúspide de la jerarquía sociopolítica adnamantina, tales como los Martínez de Azagra o los González de Ocampo, típicos ejemplos de familias que prosperaron gracias a su dedicación a la explotación de rebaños de ganado ovino trashumante, al comercio de lanas y a otras actividades vinculadas al mundo financiero. Pero también se ha de tener en cuenta que varios prominentes representantes de estas nuevas familias concertaron matrimonios con miembros de la familia Lainez, y otras de indudable origen judeoconverso, como la de los Coronel $^{85}$. Y por ello habría que evitar precipitarse a la hora de concluir que estas entraron en proceso de decadencia en la segunda mitad del siglo XVI, pues no se dispone

\footnotetext{
${ }^{85}$ Noticias que lo prueban, tomadas de las probanzas para entrada en las Órdenes Militares en DávILA, 1967.
} 
de momento de una reconstrucción detallada de las trayectorias de sus diferentes miembros en este período, que quizás pudiese llevarse a cabo sin demasiada dificultad mediante la utilización intensiva de los libros parroquiales. Mientras esta tarea no se realice, consideramos precipitado aventurar que la familia Lainez, por la simple razón de la progresiva disminución de la frecuencia con que el apellido aparece en las fuentes documentales, entró en un irreversible proceso de decadencia. Y, por supuesto, menos justificable resultaría aún atribuir ese pretendido proceso a actuaciones de la Inquisición o al sentimiento anti-converso prevaleciente en la sociedad castellana de los siglos XVI y XVII, pues ningún indicio documental de peso contribuye por el momento a corroborar dicha hipótesis.

Recibido: 11/02/2014

Aceptado: 09/06/2014 


\section{BIBLIOGRAFÍA CITADA}

Álvarez García, Carlos (1990): «Los judíos y la Hacienda Real bajo el reinado de los Reyes Católicos. Una compañía de arrendadores de rentas reales», en Las Tres Culturas en la Corona de Castilla y los Sefardies (Valladolid: Junta de Castilla y León), 87-125.

Calderón Ortega, José Manuel (1993): «Médicos, arrendadores y prestamistas de la casa de Alba durante el siglo XV», en Proyección Histórica de España en sus tres culturas: Castilla y León, América y el Mediterráneo (Valladolid: Junta de Castilla y León), vol. I, 31-35.

Cantera Burgos, Francisco (1976): «Conversos y judaizantes en la provincia de Soria (Con especial referencia a los Lainez)», Revista de Dialectología y Tradiciones Populares 32, 87-102.

Cantera Burgos, Francisco y Carlos Carrete Parrondo (1972): «La judería de Buitrago», Sefarad 32, 3-87.

Carrete Parrondo, Carlos y Carolina Fraile Conde (1987): Los judeoconversos de Almazán, 1501-1505. Origen familiar de los Lainez [= Fontes Iudaeorum Regni Castellae, IV] (Salamanca: Universidad Pontificia de Salamanca).

CAStaño GonzÁlez, Javier (1994): Las comunidades judías en el obispado de Sigüenza en la Baja Edad Media: Transformación y disgregación del judaísmo en Castilla a fines de la Edad Media (Madrid: Universidad Complutense de Madrid, tesis doctoral).

Cereceda, Feliciano (1945-1946): Diego Láinez en la Europa religiosa de su tiempo: 1512-1565 (Madrid: Instituto de Cultura Hispánica), 2 vóls.

DÁvila JALón, Valentín (1967): Nobiliario de Soria (Madrid: Talleres Prensa Española).

Diago Hernando, Máximo (1989): «El comercio de la lana en Soria en época de los Reyes Católicos», Celtiberia 77-78, 25-75.

Diago Hernando, Máximo (1992a): «Judíos y judeoconversos en Soria en el siglo Xv», Celtiberia 83, 225-253.

Diago Hernando, Máximo (1992b): «Ganaderos trashumantes y mercaderes de lanas en Molina y su Tierra durante el reinado de los Reyes Católicos», Wad-al-Hayara 19, 129-149.

Diago Hernando, Máximo (1993a): «El protonotario Lucena en su entorno sociopolítico. Nuevos datos sobre su biografía», Sefarad 53, 249-272. 
Diago Hernando, Máximo (1993b): «Almazán en época de los Reyes Católicos. Estructura social de una pequeña capital de estado señorial», En la España Medieval 16, 239-264.

Diago Hernando, Máximo (1993c): Estructuras de poder en Soria a fines de la Edad Media (Valladolid: Junta de Castilla y León).

Diago Hernando, Máximo (1996): «El ascenso sociopolítico de los judeoconversos en la Castilla del siglo XVI. El ejemplo de la familia Beltrán en Soria», Sefarad 56, 227-250.

Diago Hernando, Máximo (2002): «Efectos del decreto de expulsión de 1492 sobre el grupo de mercaderes y financieros judíos de la ciudad de Soria», en Elena Romero (ed.), Judaísmo hispano: Estudios en memoria de José Luis Lacave Riaño (Madrid: CSIC), 749-764.

Diago Hernando, Máximo (2009): «Mercaderes exportadores de lanas en la ciudad de Soria durante los siglos XVI y XVII», Celtiberia 103, 5-60.

Diago Hernando, Máximo (2011): «El factor religioso en la actividad política y social de los linajes de alta nobleza en la región soriana a fines de la Edad Media», Hispania Sacra 127, 7-39.

Diago Hernando, Máximo (2013): «El endeudamiento de la alta nobleza castellana durante la primera mitad del siglo XVI: El caso del segundo conde de Monteagudo (1506-1547)», Chronica Nova 39, 175-203.

LADERo QuesAdA, Miguel-Ángel (2003): «Coronel, 1492: De la aristocracia judía a la nobleza cristiana en la España de los Reyes Católicos», Boletín de la Real Academia de la Historia 200-201, 11-24.

LAPEYRE, Henri (1981): El comercio exterior de Castilla a través de las aduanas de Felipe II (Valladolid: Universidad de Valladolid).

Martín Galán, Manuel (2011-2012): «La familia seguntino-atencina del padre Diego Laínez, S. J.», Anales Seguntinos IX / 26, 79-98.

Martín Galán, Manuel (2012): «El adnamantino Diego Laínez, S. J., converso e hidalgo», Celtiberia 106, 53-72.

Martínez de Azagra y Beladiez, Andrés (1933): El padre Diego Lainez. Segundo prepósito general de la Compañía de Jesús (Madrid: V. Suárez).

Netanyahu, Benzion (2002²): Los marranos españoles (Valladolid: Junta de Castilla y León). 
Netanyahu, Benzion (2005): De la anarquía a la Inquisición. Estudios sobre los conversos en España durante la Baja Edad Media (Madrid: La Esfera de los Libros).

Pérez Ramírez, Dimas (1982): Catálogo del Archivo de la Inquisición de Cuenca (Madrid: Fundación Universitaria Española).

RibadEneIRA, Pedro de (1944): Vida del padre Diego Laínez (Madrid: Ediciones Atlas).

SuÁREz Fernández, Luis (1964): Documentos acerca de la expulsión de los judíos (Valladolid: CSIC). 